Article

\title{
High-Pressure Treatment of Non-Hydrated Flour Affects Structural Characteristics and Hydration
}

\author{
Sabina Jakobi, Mario Jekle * (D) and Thomas Becker \\ Research Group Cereal Technology and Process Engineering, Institute of Brewing and Beverage Technology, \\ Technical University of Munich, 85354 Freising, Germany; sabina.jakobi@tum.de (S.J.); tb@tum.de (T.B.) \\ * Correspondence: mjekle@tum.de; Tel.: +49-8161-71-3669; Fax: +49-8161-3883
}

Received: 27 April 2018; Accepted: 14 May 2018; Published: 16 May 2018

\begin{abstract}
In recent years, high-pressure treatment (HPT) has become an established process concerning the preservation of food. However, studies dealing with the structural, and consequently functional modification of non-hydrated starchy matrices (moisture content $\leq 15 \%$ ) by HPT are missing. To close this knowledge gap, pressure $(0-600 \mathrm{MPa}, 10 \mathrm{~min})$ and pressurization time depending (0-20 min, $450 \mathrm{MPa}$ ) alterations of wheat flour were investigated. Pressure rise from 0 to $600 \mathrm{MPa}$ or pressurization time rise from 0 to $20 \mathrm{~min}$ resulted in a decline of amylopectin content from $68.3 \pm 2.0 \%$ to $59.7 \pm 1.5 \%$ (linearly, $R^{2}=0.83$ ) and $59.6 \pm 0.7 \%$ (sigmoidal), respectively. Thereby, detectable total amount of starch decreased from $77.7 \pm 0.8 \%$ linearly to $67.6 \pm 1.7 \%$, and sigmoidal, to $69.4 \pm 0.4 \%$, respectively. Increase in pressure caused a linear decrease in gelatinization enthalpy of $33.2 \pm 5.6 \%$, and linear increase in hydration properties by $11.0 \pm 0.6 \%$. The study revealed structural and technological relevant alterations of starch-based food matrices with low moisture content by $\mathrm{HPT}$, which must be taken into consideration during processing and preservation of food.
\end{abstract}

Keywords: starch modification; wheat flour; physical modification; starch alteration

\section{Introduction}

In recent years, consumer expectations on safety, sensory, and nutritive characteristics of processed food have increased, resulting in the evolution of novel processing technologies as high-pressure treatment (HPT). Thereby in the beverage industry, HPT diminishes the microbial load of products without significantly affecting quality parameters [1,2]. However, studies performed on cereal biopolymers revealed HPT induced alterations of matrices, resulting in the usage of HPT for the functionalization and beneficial modification of product quality [3-6]. In gluten-free products, HPT of corn or rice starches resulted in a reduced staling rate of breadcrumbs due to structural alterations of starch, and thus, extended the shelf-life of the products [7].

Although in some food matrices, HPT should not cause alteration of covalent bonds and applied pressure should have minimal effects on processed food [8], research dealing with starchy matrices investigated great changes of polymers resulting in modified enzymatic reactions. Pressure-treated potato starch or barley/wheat flour slurries exhibited a higher enzymatic digestion, due to the increased accessibility of starch, boosting the content of reducing sugars $[9,10]$. Besides changes in matrix composition, HPT alterations of starch are monitored visually by the transformation of starch granules from a spherical/elliptical to an irregular and ruptured shape [9], as well as the loss of birefringence [11,12]. Granular destruction of starch, in turn, increased swelling and initial viscosity when pressures above $500 \mathrm{MPa}$ are applied [12,13].

To predict the extent of high pressure-induced starch modification, the knowledge of influencing factors is indispensable. Kudta and Tomasik observed a pressure and time dependent structural modification of starch [14]. Thereby, HPT of starch in aqueous solution resulted in significant 
changes of starch, however, (pea) starch suspended in ethanol exhibited no structural and functional changes [13]. Even the addition of salt, as ferric chlorides, to aqueous media affected the modification process [15]. Furthermore, intrinsic factors, such as type of starch (A, B, C) [16], starch composition as amylose/amylopectin ratio $[17,18]$, and the origin of starch $[17,19]$ influence the effectiveness of pressure treatments.

To date, investigation on the impact of HPT on starch were performed mainly in starch-water slurries [20]. However, during several cereal processing steps, such as grinding, starch is exposed to high pressure without the addition of extra water. Since HPT resulted in a partial replacement of internal starch hydrogen bonds and gelatinization of starch, it is assumed that former exploration cannot be transferred easily to high-pressure treatments on starch or flour in powdered state $(\leq 14 \%)$. Insights into the structural alteration of high pressure on starch in cereal matrices, such as flour, are essential to understand starch-modifying processes during grinding and milling. With the aid of highly compressible vials containing the wheat flour sample, HPT could be successfully applied to non-hydrated wheat flour. Thus, the impact of varied pressure (up to $600 \mathrm{MPa}$ ) and pressurization time (up to $20 \mathrm{~min}$ ) on flour characteristics was determined. This study presents the effects of HPT on the structural and functional modification of wheat flour, and on this basis, enables the investigation of HPT on low-moisture products.

\section{Materials and Methods}

\subsection{Material}

High pressure was applied to commercial wheat flour (Type 550, variety "Akteur") provided by Rosenmühle GmBH (Ergolding, Germany). The moisture content of the flour was determined according to the approved method of the AACC 44-40 (2000). Moisture content was constant at $14.64 \pm 0.27 \%$ before and after treatment. The protein content (10.55 $\pm 0.03 \%$ flours DM (dry matter)) was evaluated using Kjeldahl method AACC 46-12.01 with a conversion factor of 5.7. Ash content was $0.67 \pm 0.02 \mathrm{~g} / 100 \mathrm{~g}$ analyzed in accordance to AACC 08-12.

\subsection{High-Pressure Treatment}

HPT experiments were performed on a self-constructed high-pressure device at the Chair of Technical Microbiology at Technical University of Munich. Wheat flour was filled in elastic cryotubes, slightly compressed and hermetically sealed. The surrounding housing was filled with polyethylene-glycol-water to achieve a satisfying pressure transfer to the sample tubes. In two experimental test series (Table 1), the impact of pressurization time (at constant pressure) and of pressure (at constant pressurization time) was analyzed. Depending on the applied pressure, pressure build-up varied between 0.75 and $3.00 \mathrm{~min}$ (Table 1). The pressurization time started when the applied pressure was reached. All pressure treatments were performed at least in triplicates.

Table 1. High-pressure treatment (HPT) parameters applied to wheat flour sample and pressure built-up time.

\begin{tabular}{ccc}
\hline Pressure (MPa) & Pressurization Time (min) & Pressure Build-Up (min) \\
\hline 0 & 10 & 0 \\
150 & 10 & 0.75 \\
300 & 10 & 1.50 \\
450 & 10 & 2.25 \\
600 & 10 & 3.00 \\
450 & 1 & 2.25 \\
450 & 2 & 2.25 \\
450 & 5 & 2.25 \\
450 & 10 & 2.25 \\
450 & 20 & 2.25 \\
\hline
\end{tabular}




\subsection{Molecular Structure of Starch}

Determination of glucose, maltose, maltotriose, as well as fructose and saccharose, was performed using HPAEC-ED (high-performance anion-exchange chromatography with electrochemical detector from Dionex Softron GmbH (Germering, Germany). Flours were dissolved in a methanol-water (1:1) solution ( $1 \mathrm{~g} /$ flour $/ 8 \mathrm{~mL}$ solvent) to inhibit enzymatic reactions. Afterwards, samples were filtered through $0.45 \mu \mathrm{m}$ syringe filters and stored at $-18 \pm 1{ }^{\circ} \mathrm{C}$ before the analysis. Relative amylose content was determined with an amylose/amylopectin assay kit (Megazyme International Ireland Ltd., Wicklow, Ireland). Total starch content was analyzed according to the AACC Methode 76-13.01 using Total Starch Enzyme Kit from Megazyme International Ireland Ltd. (Wicklow, Ireland). To purify starch and remove interfering dextrin of the sample, flour samples were purified in concentrated ethanol solution $(80 \%)$.

\subsection{Crystalline Properties}

Impact of HPT on crystalline structures of starch was studied using dynamic scanning calorimetry (DSC) (Pyris Diamond, Perkin Elmer, Waltham, MA, USA) equipped with a cooling system (Intracooler $2 \mathrm{P}$ ). Flour samples were mixed with distilled water (flour/water $=1: 3$ ), filled in aluminum pans (20-35 mg) and hermetically sealed. After 2 min equilibration time at $-40^{\circ} \mathrm{C}$, samples were heated from $-40{ }^{\circ} \mathrm{C}$ to $+95{ }^{\circ} \mathrm{C}$, and held again for $2 \mathrm{~min}$. The gelatinization enthalpy (calculated from the peak endotherm) describes the amount of energy which is necessary to melt crystalline parts of starch during heating.

\subsection{Granular Structure}

Particle size distribution prior and after HPT was analyzed by static light scattering using Mastersizer 3000 equipped with AeroS unit for dry measurements (Malvern Instruments Ltd., Worcestershire, UK). "Mie Theory" was applied to calculate the particle size distribution using a refractive index of 1.59, the "general purpose mode", and an obscuration ranging between 2 and $8 \%$ during measurements. All measurements were performed in triplicates.

\subsection{Starch Modification Degree}

Starch modification degree (formerly known as starch damage) was determined according to the approved method (AACC method 76-31.01) using the Starch Damage Assay Kit (Megazyme International Ireland Ltd., Wicklow, Ireland). The starch modification degree (SMD) specifies the amount of starch which can be hydrolyzed at $40{ }^{\circ} \mathrm{C}$ by fungal $\alpha$-amylase to low molecular weight dextrin, and is calculated using Formula (1):

$$
\mathrm{SMD}=\Delta \mathrm{E} \times \mathrm{F} \times 60 \times(1 / 1000) \times(100 / \mathrm{W}) \times(162 / 180),
$$

with SMD = starch modification degree (\%), $\Delta \mathrm{E}=$ absorbance (reaction) read against the reagent blank, $\mathrm{F}=(150 \mu \mathrm{g}$ of glucose $) /($ absorbance of $150 \mu \mathrm{g}$ of glucose $), \mathrm{W}=$ sample weight $(\mathrm{mg})$.

\subsection{Hydration Properties}

The solvent (water) retention capacity (WRC) of flours states the amount of water which can be bound by the sample after centrifugation at low rotational speed (AACC 56-11.02). The approved method had to be modified due to the low sample amount. The ratio flour/solvent remained constant, however, flour weight was reduced to $1.00 \pm 0.05 \mathrm{~g}$, and distilled water to $5.00 \pm 0.05 \mathrm{~g}$. 


\subsection{Statistical Evaluation}

The statistical analysis was performed using JMP ${ }^{\circledR}$ Pro (Version 12.2.0, JMP Software, SAS Institute Inc., Cary, NC, USA). The effects of HPT on starch structures and functionality were determined using Tukey's pairwise comparisons with a confidence level of $95.0 \%$ with ANOVA.

\section{Results and Discussion}

\subsection{Molecular Alterations of Starch}

Starch mainly consists of the highly branched polymer amylopectin and the linear glucan amylose, which determine the functional properties of starch. The polymer constitution of starch in flour samples gives information of the origin of starch and provides fundamental insights into the extent of stress acting on starch during physical treatments. As shown in Table 2, with the increase in pressure from 0 to $600 \mathrm{MPa}$, a significant rise of relative amylose content from $31.7 \pm 1.7 \%$ of total starch to $40.3 \pm 1.2 \%$ of total starch (linearly, $R^{2}=0.834$ ), and decrease of total starch from $77.7 \pm 0.8 \%$ to $67.6 \pm 1.7 \%$ (linearly, $R^{2}=0.892$ ) occurred. The simultaneous increase of percentage amylose content and decrease of total starch can be reduced to the destruction of the starch polymer amylopectin. It is well known from literature, that the degradation of the highly-branched polymer amylopectin $\left(\sim 10^{8} \mathrm{Da}\right.$ in comparison to amylose $\left.\sim 10^{6} \mathrm{Da}\right)$ is favored when physical forces are applied to pure starch or flours [21,22], explainable by the higher molecular weight and rigidity of amylopectin. The predominant degradation of amylopectin to low molecular weight dextrin or the debranching of this polymer resulted in a percentage rise of amylose in total starch. However, the extent of the degradation of total starch content was surprising. Applied pressure of $600 \mathrm{MPa}$ caused a reduction of the starch content of $13.0 \%$, despite a low moisture content in the present flour samples $(14.64 \pm 0.27 \%)$. Extrusion processes of starchy matrices are known to reduce, extremely, the hydrodynamic radius of starches caused by the splitting of polymer chains, as well [23]. However, this study was performed in matrices with glycerol/water plasticizer of 30 or $40 \%$, facilitating cleavage of polymer chains.

Table 2. Molecular modification of starch in wheat flour visualized by the maltose content, amylose content, and total starch content in dependency of pressurization time and pressure, $\bar{x} \pm \mathrm{SD}, n=3, \mathrm{DM}$ : dry matter.

\begin{tabular}{|c|c|c|c|c|c|c|c|}
\hline \multicolumn{4}{|c|}{ Variation of Pressure (for 10 min Pressurization Time) } & \multicolumn{4}{|c|}{ Variation of Pressurization Time (at $450 \mathrm{MPa}$ ) } \\
\hline $\begin{array}{l}\text { Pressure } \\
\text { (MPa) }\end{array}$ & $\begin{array}{c}\text { Maltose } \\
\text { (mg/g Flour) }\end{array}$ & $\begin{array}{l}\text { Amylose } \\
\text { (\% of Total } \\
\text { Starch) }\end{array}$ & $\begin{array}{l}\text { Total Starch } \\
\text { (\% DM) }\end{array}$ & $\begin{array}{l}\text { Pressurization } \\
\text { Time (min) }\end{array}$ & $\begin{array}{l}\text { Maltose } \\
\text { (mg/g } \\
\text { Flour) }\end{array}$ & $\begin{array}{l}\text { Amylose } \\
\text { (\% of Total } \\
\text { Starch) }\end{array}$ & $\begin{array}{l}\text { Total Starch } \\
\text { (\% DM) }\end{array}$ \\
\hline 0 & $0.8 \pm 0.1^{\mathrm{A}}$ & $31.7 \pm 1.7^{\mathrm{C}}$ & $77.7 \pm 0.8^{\mathrm{A}}$ & 0 & $0.8 \pm 0.1^{\mathrm{A}}$ & $31.7 \pm 1.7^{\mathrm{C}}$ & $77.7 \pm 0.8^{\mathrm{A}}$ \\
\hline 150 & $0.8 \pm 0.1^{\mathrm{A}, \mathrm{B}}$ & $33.2 \pm 1.2^{\mathrm{B}, \mathrm{C}}$ & $76.8 \pm 0.8^{\mathrm{A}, \mathrm{B}}$ & 1 & $0.7 \pm 0.1^{\mathrm{A}}$ & $34.2 \pm 1.0^{\mathrm{B}, \mathrm{C}}$ & $76.2 \pm 0.9^{\mathrm{A}, \mathrm{B}}$ \\
\hline 300 & $0.6 \pm 0.1^{\mathrm{B}}$ & $35.2 \pm 0.5^{\mathrm{B}, \mathrm{C}}$ & $74.0 \pm 0.5^{\mathrm{B}, \mathrm{C}}$ & 2 & $0.6 \pm 0.1^{\mathrm{A}}$ & $35.7 \pm 0.7^{\mathrm{B}}$ & $74.7 \pm 0.5^{\mathrm{B}, \mathrm{C}}$ \\
\hline 450 & $0.6 \pm 0.0^{\mathrm{B}}$ & $37.0 \pm 1.3^{\mathrm{A}, \mathrm{B}}$ & $71.7 \pm 0.7^{\mathrm{C}}$ & 5 & $0.7 \pm 0.2^{\mathrm{A}}$ & $36.2 \pm 0.6^{\mathrm{B}}$ & $73.7 \pm 0.3^{\mathrm{C}, \mathrm{D}}$ \\
\hline \multirow[t]{2}{*}{600} & $0.6 \pm 0.1^{\mathrm{B}}$ & $40.3 \pm 1.2^{\mathrm{A}}$ & $67.6 \pm 1.7^{\mathrm{D}}$ & 10 & $0.6 \pm 0.0^{\mathrm{A}}$ & $37.0 \pm 1.3^{\mathrm{A}, \mathrm{B}}$ & $71.7 \pm 0.7^{\mathrm{D}}$ \\
\hline & & & & 20 & $0.6 \pm 0.1^{\mathrm{A}}$ & $40.4 \pm 0.7^{\mathrm{A}}$ & $69.4 \pm 0.4^{\mathrm{E}}$ \\
\hline
\end{tabular}

Different letters in columns mark statistically significant differences between means $(p \leq 0.05)$.

Although the determination of total starch content using a Megazyme assay kit presents a fast and reproductive method, it is questionable if an underestimation of the dextrin content after severe physical treatment of starchy matrices occurs. In the first step of this assay, interfering substances are removed by washing the sample in ethanol. The cleavage of starch leads to the formation of low molecular weight fragments showing a higher solubility than starch. Those dextrins are removed prior to the enzymatic digestion, and thus, not detected.

A slight (significant) decrease of maltose content was further investigated, when pressure increased from 0 to $600 \mathrm{MPa}(0.8 \pm 0.1$ to $0.6 \pm 0.1 \mathrm{mg} / \mathrm{g}$ flour $)$. To date, it remains unclear if the reduction of maltose content is due to a mechanically induced splitting of the disaccharide. An enzymatic hydrolyzation of starch was excluded, since enzymatic degradation of maltose would 
cause an increase in glucose content, which could not be determined so far (data not shown), and furthermore, temperature did not rise during the pressure treatment above $\left(30 \pm 1{ }^{\circ} \mathrm{C}\right)$. Although decrease in maltose content is negligible for practical application, it provides insights into the mechanism of high pressure on the molecular modification of starch.

Surprisingly, decrease in maltose content could not be determined with an increase in pressurization time from 0 to $20 \mathrm{~min}$ at a pressure level of $450 \mathrm{MPa}$. Furthermore, the analysis of the impact of pressurization time on starch structures elucidates the time-dependent destruction of starch. Due to the natural logarithmic destructive behavior of starch with increase in pressurization time, during the first $5 \mathrm{~min}$ of the treatment, the total starch content decreased about $5.1 \%$; within the following $15 \mathrm{~min}$ ( $\min 5-20$ ), starch content only decreased about $5.8 \%$.

Due to the huge impact of HPT, even in low moisture matrices on starch, pressure treatments of food systems should not be neglected. Since a favored destruction of amylopectin occurred during HPT, measurements of starch crystallinity are necessary to predict the modified behavior of HPT starches during non-isothermal processes.

\subsection{Alterations in Gelatinization Properties and Starch Modification Degree of Flours}

Alterations in starch gelatinization properties on nanoscopic scale can be visualized using differential scanning calorimetry. In starch-water suspensions, a destruction of starch crystallinity was already determined by differential scanning calorimetry (DSC) and X-ray method [24]. These results coincide with findings in these studies, despite the significant lower moisture content in the present study. With increase in pressure, a linear decrease in the gelatinization enthalpy of HPT samples from $5.0 \pm 0.1 \mathrm{~J} / \mathrm{g}$ to $3.4 \pm 0.4 \mathrm{~J} / \mathrm{g}$ was noticed $\left(R^{2}=0.851\right)$ (Figure 1$)$. Thus, the pressure treatment of $600 \mathrm{MPa}$ resulted in a reduction of total starch and crystallinity of 13.0 and $32.6 \%$, respectively. Consequently, reduction of the total starch content could entail the multiple decline of crystallinity. Furthermore, the severe reduction of gelatinization enthalpy could be referred to a partial gelatinization of starch. In high-moisture matrices, $15-88 \%$ of wheat starch was melted, when pressure between 300 and $500 \mathrm{MPa}$ was applied [25]. Thus, a partial gelatinization of starch in HPT non-hydrated samples is possible, causing an accelerated decline in gelatinization enthalpy. The stepwise increase in pressurization time up to $20 \mathrm{~min}$ caused a reduction of gelatinization enthalpy to $3.8 \pm 0.3 \mathrm{~J} / \mathrm{g}$, following a natural logarithmic curve shape (comparable to total starch content): within the first minute of treatment (plus pressure built-up time), gelatinization enthalpy decreased to $4.3 \pm 0.2 \mathrm{~J} / \mathrm{g}$. Afterward, a decelerated decline in gelatinization enthalpy was noticed, which is consistent with findings of Bauer and Knorr [26]. In general, severe alterations of starch crystallinity were preceded by destruction of granular constitution of starch, and thus facilitated enzymatic digestion.

The starch modification degree (SMD) increased with pressure level (up to $600 \mathrm{MPa}$ ) by $37 \%$ (linear dependency, $R^{2}=0.97$ ). A dependency of SMD from the applied pressure was also revealed by Ahmed et al. on matrices containing 20-50\% wheat flour [27]. The rise in pressurization time (up to $20 \mathrm{~min}$ ) resulted in an increase of SMD of $38 \%$. At the applied pressure of $450 \mathrm{MPa}$, main alterations in SMD occurred during the first minute of treatment. Thereby, SMD was raised from $4.40 \pm 0.13 \%$ to $5.66 \pm 0.15 \%$, and stayed constant during the following $9 \mathrm{~min}$, demonstrating the need for a detailed control of HPT-induced alterations of starchy matrices, especially during short HPT.

Thereby, the starch modification degree of flours is a key value for the enzymatic degradation of flour particles by amylases during fermentation processes. To draw conclusions regarding the enzymatic hydrolysis and as well to monitor physically-induced changes of flours, the particle size distribution of flours is often determined. Furthermore, changes on microscopic scale can be identified using static light scattering. 

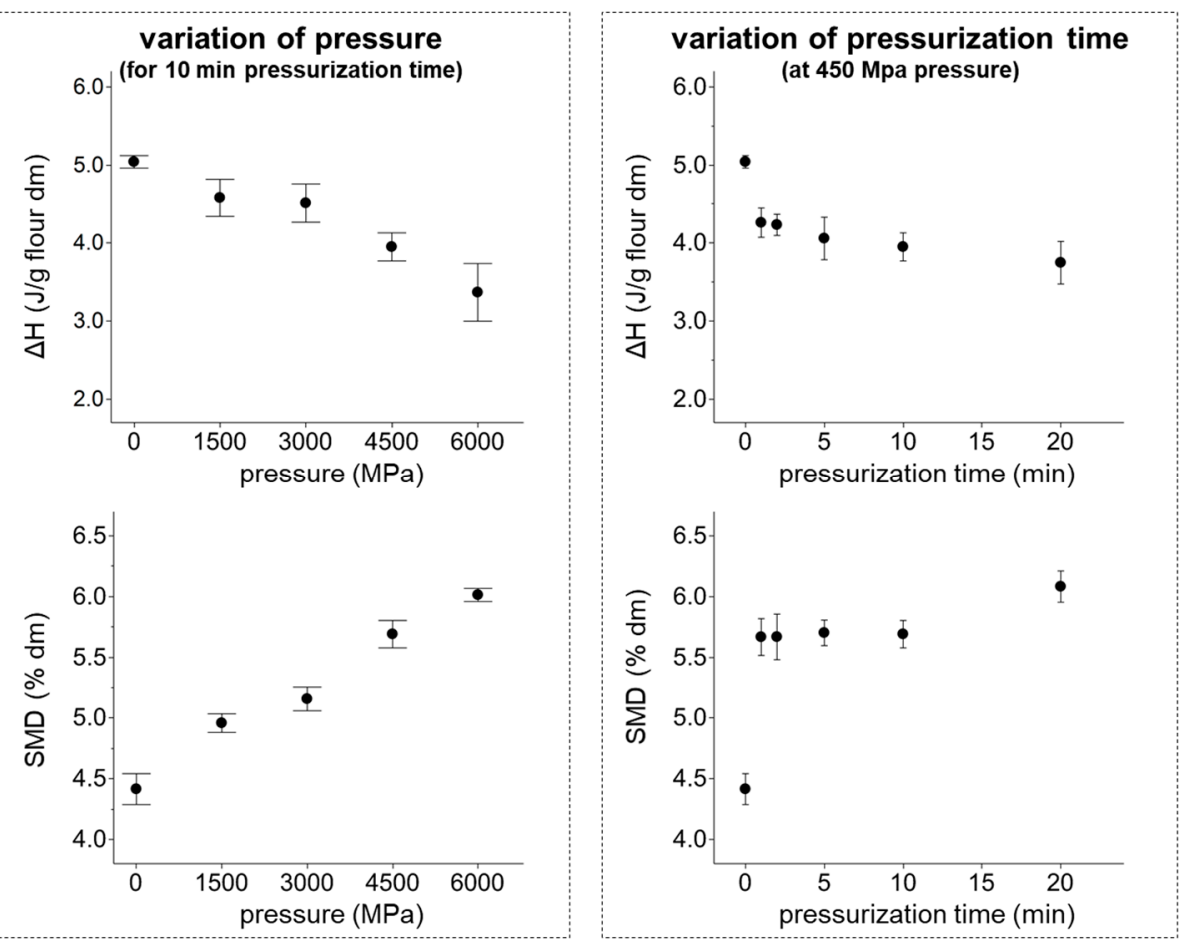

Figure 1. Impact of pressure and pressurization time on the gelatinization enthalpy $(\Delta \mathrm{H})$ and starch modification degree (SMD) of wheat flour, $\bar{x} \pm \mathrm{SD}, n=3$.

\subsection{Granular Modification of Wheat Flour Particles}

Wheat flours, modified by grinding procedures, showed in previous studies a good correlation of SMD and the particle size distribution, so that authors assumed that rise in SMD was caused by the surface enlargement due to the particle size reduction [22]. However, for HPT flours, no reduction of bigger flour particles was visible, as demonstrated by the $\mathrm{D}_{3,90}$ of the pressure and pressurization time test series (Table 3). Low pressurization time of $1 \mathrm{~min}$ caused a significant reduction of the medium particle size $D_{3,50}$ from $90.4 \pm 0.8$ to $74.0 \pm 4.7 \mu \mathrm{m}$ without any alterations for longer treatments. A comparable behavior was detected for the pressure level, whereby for pressure treatments above $150 \mathrm{MPa}$, no significant changes of the medium particle size $\mathrm{D}_{3,50}$ were noticed anymore. In literature, contradictory results and dependencies concerning particle size alterations of HPT starches were found: while application of high pressure caused a disruption of bigger particles in high moisture wheat slurry $(>50 \%)$ [27], an increase of particle size of starch by five- to six-fold was noticed in almond milk or wheat slurries containing sugars [28,29]. However, in the present study, no alterations of flour particles were visible for low moisture matrixes as non-hydrated wheat flour (14\%), which is in accordance to the findings of Douzals on wheat starch suspensions (5\% DM) [30].

Since particle size distribution (PSD) values are in contrast with the development of SMD under pressure treatments in non-hydrated matrices, where a continuous increase in SMD over the whole pressure range was measured, PSD is not, in general, an adequate analytical method for the prediction of the accessibility of particles for enzymatic digestion. Consequently, surface alterations of wheat flour particles occur, which is not related to the particle size reduction. Changes of starch-gluten agglomerates are known to occur by mechanical treatments, for example grinding, even in low moisture matrices, due to the removal of starch-covering proteins by friction forces. However, since during HPT, 3-dimensional and low friction forces are applied on starch-protein agglomerates, no removal of starch-covering proteins was expected, increasing the accessibility of starch. Therefore, possible explanations for the rise in SMD are microcracks and the deformation of starch granules, which enlarge 
the surface of starch, and consequently, enzymatic accessibility, without altering noticeably the particle size distribution.

Table 3. Granular alterations of wheat flour particles determined by the particle size distribution (volume) in dependency of pressurization time and pressure, $\bar{x} \pm \mathrm{SD}, n=3$.

\begin{tabular}{|c|c|c|c|c|c|c|c|}
\hline \multicolumn{4}{|c|}{ Variation of Pressure (10 min Pressurization Time) } & \multicolumn{4}{|c|}{ Variation of Pressurization Time (450 MPa) } \\
\hline $\begin{array}{l}\text { Pressure } \\
\text { (MPa) }\end{array}$ & $\mathrm{D}_{3,10}(\mu \mathrm{m})$ & $\mathrm{D}_{3,50}(\mu \mathrm{m})$ & $\mathrm{D}_{3,90}(\mu \mathrm{m})$ & $\begin{array}{l}\text { Pressurization } \\
\text { Time (min) }\end{array}$ & $\mathrm{D}_{3,10}(\mu \mathrm{m})$ & $\mathrm{D}_{3,50}(\mu \mathrm{m})$ & $\mathrm{D}_{3,90}(\mu \mathrm{m})$ \\
\hline 0 & $24.2 \pm 0.4^{\mathrm{A}}$ & $90.4 \pm 0.8^{\mathrm{A}}$ & $185.2 \pm 5.9^{\mathrm{A}}$ & 0 & $24.2 \pm 0.4^{\mathrm{A}}$ & $90.4 \pm 0.8^{\mathrm{A}}$ & $185.2 \pm 5.9^{\mathrm{A}}$ \\
\hline 150 & $19.8 \pm 0.4^{\mathrm{A}}$ & $81.5 \pm 1.7^{\text {B }}$ & $184.5 \pm 7.3^{\text {В }}$ & 1 & $17.6 \pm 1.1^{C}$ & $74.0 \pm 4.7^{B}$ & $182.8 \pm 4.5^{\mathrm{A}, \mathrm{B}, \mathrm{C}}$ \\
\hline 300 & $19.9 \pm 0.6^{\mathrm{A}}$ & $82.2 \pm 1.5^{\text {B }}$ & $184.4 \pm 2.3^{\text {B }}$ & 2 & $17.4 \pm 1.3^{C}$ & $73.5 \pm 5.1^{\mathrm{B}}$ & $179.0 \pm 3.3^{\mathrm{B}, \mathrm{C}}$ \\
\hline 450 & $20.2 \pm 2.1^{\mathrm{A}}$ & $81.0 \pm 6.5^{B}$ & $184.3 \pm 6.1^{\text {B }}$ & 5 & $18.0 \pm 1.4^{\mathrm{C}}$ & $75.9 \pm 5.2^{B}$ & $177.9 \pm 3.0^{C}$ \\
\hline \multirow[t]{2}{*}{600} & $21.1 \pm 2.0^{\mathrm{A}}$ & $83.4 \pm 7.1^{\mathrm{B}}$ & $191.7 \pm 9.9^{\mathrm{B}}$ & 10 & $20.2 \pm 2.1^{B}$ & $77.1 \pm 4.9^{\mathrm{B}}$ & $184.3 \pm 6.1^{\mathrm{A}, \mathrm{B}}$ \\
\hline & & & & 20 & $17.0 \pm 0.9^{C}$ & $71.7 \pm 3.8^{\mathrm{B}}$ & $179.6 \pm 3.7^{\mathrm{A}, \mathrm{B}, \mathrm{C}}$ \\
\hline
\end{tabular}

Different letters in columns mark statistically significant differences between means $(p \leq 0.05)$.

To summarize, high pressure-treated flours show comparable molecular (total starch content), crystalline (gelatinization enthalpy) and surface-related (enzymatic accessibility) alterations, which cannot be correlated to the modification of particle size. Thus, using static light scattering, HPT-caused alterations of wheat flours cannot be determined. For the application of pressure-treated starchy matrices in food industry, beside structural alterations, the functional properties of HPT flours are of special interest, too.

\subsection{Facilitated Hydration of HPT Flours}

The water retention capacity (WRC) of flours describes the amount of water which can be bound by flours after centrifugation. For an increase in WRC, a high accessibility of flours to water is prerequisite. Existing studies in high-moisture matrices have already shown a dependency of pressure and the swelling index of wheat starch [31], and a higher retention capacity of medium moisture matrices $(\sim 40 \%)$ treated by pressure treatment at $600 \mathrm{MPa}$ [32]. Those findings are also mainly transferable to non-hydrated, starch-based flours. Both test series (pressure level and pressurization time) led to a significant increase in WRC, according to the curve shapes of SMD (compared in Figure 2). The increase in pressure up to $600 \mathrm{MPa}$ resulted in a linear rise of WRC $\left(R^{2}=0.942\right)$ from $65.68 \pm 0.43 \%$ to $73.77 \pm 0.92 \%$. This is in agreement with findings from authors dealing with alterations of flour hydration introduced by high-pressure treatments in starch suspensions. However, less effects of high-pressure on starch or flour are expected, as in comparison to HPT of starch suspension, since the hydration highly depends on the availability of free water [33]. A pressurization time of $2 \mathrm{~min}$ at $450 \mathrm{MPa}$ caused an increase of WRC to $70.12 \pm 0.70 \%$, however, afterwards, only a slight increase of WRC was noticed $(72.91 \pm 0.67 \%$ for $20 \mathrm{~min}$ HPT). The relation of starch modification degree, pressure, and increased hydration properties of starch in dispersions was also noticed by Ahmed et al. [27]. Hence, the hypothesis can be confirmed, that high-pressure treatment of low moisture starchy matrices significantly modifies the flour particle accessibility, as demonstrated by SMD and WRC measurements, without evoking severe alterations of particle size. 

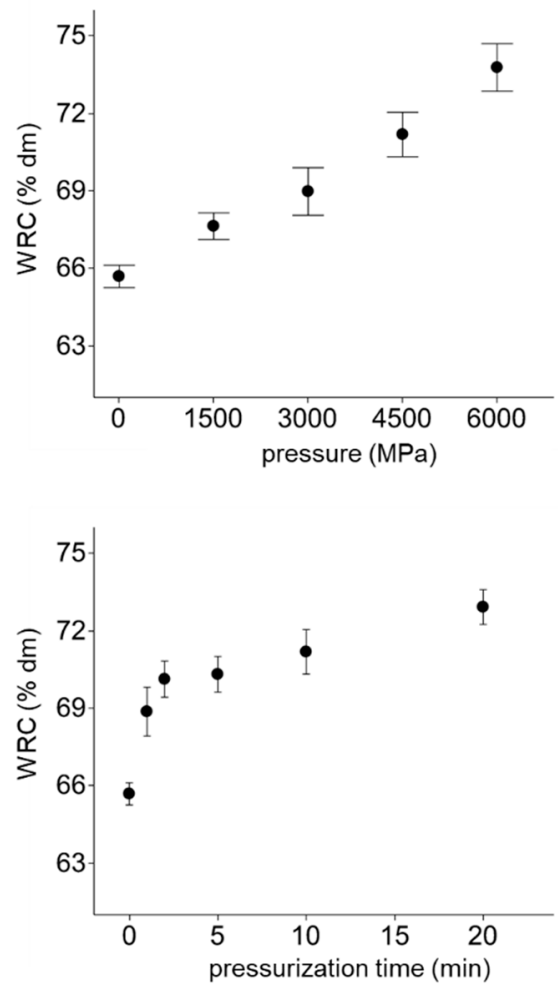

Figure 2. Impact of pressure and pressurization time on hydration properties (WRC $=$ water retention capacity) of wheat flour, $\bar{x} \pm \mathrm{SD}, n=3$.

\section{Conclusions}

High-pressure treatment of non-hydrated starch-protein particles causes structural modifications of starch, and consequently, functionality of the matrix. Thus, evaluation of high-pressure treatments of starchy food should not exclusively focus on the improvement of the microbiological stability of food products, but also consider functional alterations of the matrix by HPT. These findings are of special interest for the practical, industrial application. The reduction of microbiological stability, in combination with a better enzymatic accessibility of starch, facilitates long-term fermentation processes under controlled conditions. Since high-pressure treatments of starchy matrices, even under low moisture conditions, evoke modifications of starch, grinding processes with (proportional) compressive forces—as found in roller grinding processes—should be examined and adjusted precisely, to prevent undesired alterations. This knowledge can lead to a reconsideration of high-pressure treatments of food systems, and to a targeted selection of monitoring parameters during HPT.

Author Contributions: Conceptualization, methodology, data curation, writing-S.J.; supervision-M.J. and T.B.

Acknowledgments: This IGF Project of the FEI is supported via AiF (18679 N) within the programme for promoting the Industrial Collective Research (IGF) of the German Ministry of Economic Affairs and Energy (BMWi), based on a resolution of the German Parliament, and financed by the German Research Foundation (DFG) and the Technical University of Munich within the funding programme Open Access Publishing. Furthermore, the authors want to thank the Chair of Technical Microbiology at Technical University of Munich for the possibility to perform the experiments on the high-pressure plant of the Chair.

Conflicts of Interest: The authors declare no conflict of interest.

\section{References}

1. Bull, M.K.; Zerdin, K.; Howe, E.; Goicoechea, D.; Paramanandhan, P.; Stockman, R.; Sellahewa, J.; Szabo, E.A.; Johnson, R.L.; Stewart, C.M. The effect of high pressure processing on the microbial, physical and chemical properties of Valencia and Navel orange juice. Innov. Food Sci. Emerg. Technol. 2004, 5, 135-149. [CrossRef] 
2. Timmermans, R.A.H.; Mastwijk, H.C.; Knol, J.J.; Quataert, M.C.J.; Vervoort, L.; Van der Plancken, I.; Hendrickx, M.E.; Matser, A.M. Comparing equivalent thermal, high pressure and pulsed electric field processes for mild pasteurization of orange juice. Part I: Impact on overall quality attributes. Innov. Food Sci. Emerg. Technol. 2011, 12, 235-243. [CrossRef]

3. Balasubramaniam, V.M.; Barbosa-Cánovas, G.V.; Lelieveld, H.L.M. High Pressure Processing of Food; Food Engineering Series; Springer: New York, NY, USA, 2016; ISBN 978-1-4939-3233-7.

4. Dunford, N.T. Food and Industrial Bioproducts and Bioprocessing; Wiley-Blackwell: Hoboken, NJ, USA, 2012; ISBN 9780813821054.

5. Kim, H.-S.; Kim, B.-Y.; Baik, M.-Y. Application of Ultra High Pressure (UHP) in Starch Chemistry. Crit. Rev. Food Sci. Nutr. 2012, 52, 123-141. [CrossRef] [PubMed]

6. Liu, P.-L.; Hu, X.-S.; Shen, Q. Effect of high hydrostatic pressure on starches: A review. Starch-Stärke 2010, 62, 615-628. [CrossRef]

7. Cappa, C.; Barbosa-Cánovas, G.V.; Lucisano, M.; Mariotti, M. Effect of high pressure processing on the baking aptitude of corn starch and rice flour. LWT Food Sci. Technol. 2016, 73, 20-27. [CrossRef]

8. Muntean, M.-V.; Marian, O.; Barbieru, V.; Cătunescu, G.M.; Ranta, O.; Drocas, I.; Terhes, S. High Pressure Processing in Food Industry-Characteristics and Applications. Agric. Agric. Sci. Procedia 2016, 10, 377-383. [CrossRef]

9. Mu, T.-H.; Zhang, M.; Raad, L.; Sun, H.-N.; Wang, C. Effect of $\alpha$-Amylase Degradation on Physicochemical Properties of Pre-High Hydrostatic Pressure-Treated Potato Starch. PLoS ONE 2015, 10. [CrossRef] [PubMed]

10. Gomes, M.R.A.; Clark, R.; Ledward, D.A. Effects of high pressure on amylases and starch in wheat and barley flours. Food Chem. 1998, 63, 363-372. [CrossRef]

11. Błaszczak, W.; Valverde, S.; Fornal, J. Effect of high pressure on the structure of potato starch. Carbohydr. Polym. 2005, 59, 377-383. [CrossRef]

12. Oh, H.E.; Hemar, Y.; Anema, S.G.; Wong, M.; Neil Pinder, D. Effect of high-pressure treatment on normal rice and waxy rice starch-in-water suspensions. Carbohydr. Polym. 2008, 73, 332-343. [CrossRef]

13. Leite, T.S.; de Jesus, A.L.T.; Schmiele, M.; Tribst, A.A.L.; Cristianini, M. High pressure processing (HPP) of pea starch: Effect on the gelatinization properties. LWT Food Sci. Technol. 2017, 76, 361-369. [CrossRef]

14. Kudta, E.; Tomasik, P. The Modification of Starch by High Pressure. Part I: Air- and Oven-dried Potato Starch. Starch-Stärke 1992, 44, 167-173. [CrossRef]

15. Kudla, E.; Tomasik, P. The Modification of Starch by High Pressure. Part II: Compression of Starch with Additives. Starch-Stärke 1992, 44, 253-259. [CrossRef]

16. Stute, R.; Heilbronn, R.W.; Klingler, R.W.; Boguslawski, S.; Eshtiaghi, M.N.; Knorr, D. Effects of High Pressures Treatment on Starches. Starch-Starke 1996, 48, 399-408. [CrossRef]

17. Oh, H.E.; Pinder, D.N.; Hemar, Y.; Anema, S.G.; Wong, M. Effect of high-pressure treatment on various starch-in-water suspensions. Food Hydrocoll. 2008, 22, 150-155. [CrossRef]

18. Simonin, H.; Marzouki, S.; Guyon, C.; Orlowska, M.; Le-Bail, A.; de Lamballerie, M. Pasting properties of high-pressure-treated starch suspensions. High Press. Res. 2009, 29, 726-731. [CrossRef]

19. Liu, Y.Q.; Liu, Y.N.; Li, H.; Shen, R.L.; Li, X.H.; Yang, L.Z. The Study on Gelatinization Pressure of Starch by Ultra-High Pressure Processing. Adv. Mater. Res. 2011, 295-297, 131-134. [CrossRef]

20. Kawai, K.; Fukami, K.; Yamamoto, K. Effect of temperature on gelatinization and retrogradation in high hydrostatic pressure treatment of potato starch-water mixtures. Carbohydr. Polym. 2012, 87, 314-321. [CrossRef]

21. Dhital, S.; Shrestha, A.K.; Flanagan, B.M.; Hasjim, J.; Gidley, M.J. Cryo-milling of starch granules leads to differential effects on molecular size and conformation. Carbohydr. Polym. 2011, 84, 1133-1140. [CrossRef]

22. Jakobi, S.; Jekle, M.; Becker, T. Direct link between specific structural levels of starch and hydration properties. Carbohydr. Polym. 2018, 181, 159-166. [CrossRef] [PubMed]

23. Li, M.; Hasjim, J.; Xie, F.; Halley, P.J.; Gilbert, R.G. Shear degradation of molecular, crystalline, and granular structures of starch during extrusion. Starch-Stärke 2014, 66, 595-605. [CrossRef]

24. Liu, M.; Wu, N.-N.; Yu, G.-P.; Zhai, X.-T.; Chen, X.; Zhang, M.; Tian, X.-H.; Liu, Y.-X.; Wang, L.-P.; Tan, B. Physicochemical properties, structural properties, and in vitro digestibility of pea starch treated with high hydrostatic pressure. Starch-Stärke 2018, 70. [CrossRef]

25. Douzals, J.P.; Marechal, P.A.; Coquille, J.C.; Gervais, P. Microscopic Study of Starch Gelatinization under High Hydrostatic Pressure. J. Agric. Food Chem. 1996, 44, 1403-1408. [CrossRef] 
26. Bauer, B.A.; Knorr, D. The impact of pressure, temperature and treatment time on starches: Pressure-induced starch gelatinisation as pressure time temperature indicator for high hydrostatic pressure processing. J. Food Eng. 2005, 68, 329-334. [CrossRef]

27. Ahmed, J.; Mulla, M.Z.; Arfat, Y.A. Particle size, rheological and structural properties of whole wheat flour doughs as treated by high pressure. Int. J. Food Prop. 2017, 20, 1829-1842. [CrossRef]

28. Dhakal, S.; Giusti, M.M.; Balasubramaniam, V. Effect of high pressure processing on dispersive and aggregative properties of almond milk. J. Sci. Food Agric. 2016, 96, 3821-3830. [CrossRef] [PubMed]

29. Reineke, K.; Weich, H.; Knorr, D. The Influence of Sugars on Pressure Induced Starch Gelatinization. Procedia Food Sci. 2011, 1, 2040-2046. [CrossRef]

30. Douzals, J.P.; Perrier Cornet, J.M.; Gervais, P.; Coquille, J.C. High-Pressure Gelatinization of Wheat Starch and Properties of Pressure-Induced Gels. J. Agric. Food Chem. 1998, 46, 4824-4829. [CrossRef]

31. Douzals, J.P.; Perrier-Cornet, J.M.; Gervais, P.; Coquille, J.C. Hydration and Pressure-Temperature Phase Diagrams of Wheat Starch. In Advances in High Pressure Bioscience and Biotechnology; Springer: Berlin/Heidelberg, Germany, 1999; pp. 333-336, ISBN 978-3-642-60196-5.

32. Cappa, C.; Lucisano, M.; Barbosa-Cánovas, G.V.; Mariotti, M. Physical and structural changes induced by high pressure on corn starch, rice flour and waxy rice flour. Food Res. Int. 2016, 85, 95-103. [CrossRef] [PubMed]

33. Rumpold, B.A. Impact of High Hydrostatic Pressure on Wheat, Tapioca, and Potato Starches. Ph.D. Thesis, Technical University of Berlin, Berlin, Germany, August 2005.

(C) 2018 by the authors. Licensee MDPI, Basel, Switzerland. This article is an open access article distributed under the terms and conditions of the Creative Commons Attribution (CC BY) license (http://creativecommons.org/licenses/by/4.0/). 